\title{
Oráculo y ley. Una aproximación a la influencia política de la adivinación en la Antigüedad
}

\author{
Oracle and law. An introduction to the political influence \\ of divination in Antiquity
}

DAVID HERnÁNDEZ de LA Fuente*

\begin{abstract}
RESUMEN
Las prácticas adivinatorias han desempeñado un importante papel en diversas culturas del mundo antiguo, desde Egipto y Mesopotamia hasta el final del paganismo clásico, cuando fueron paulatinamente sustituidas por el recurso a la nueva legitimación religiosa del poder promovida por el Cristianismo. Este trabajo, que presenta una introducción centrada en aspectos del mundo griego, propone un nuevo acercamiento a este fenómeno desde una perspectiva interdisciplinaria con motivo de la mesa redonda "Adivinación y política en la Antigüedad" y su discusión, cuyos resultados presenta abreviados.
\end{abstract}

PALABRAS CLAVE:

Religión griega y romana, adivinación, teoría política clásica, derecho griego.

\begin{abstract}
Divination and mantic practices played a very important role in several cultures of the ancient world, from Egypt and Mesopotamia to the end of classical paganism, when such procedures were gradually replaced by the new means of religious legitimation that Christianism provided for politics. This paper, presenting an introduction to this phenomenon in the Greek world, puts forward a new interdisciplinary approach to the issue and, at the same time, introduces and summarizes briefly the discussion of the panel «Divination and politics in the ancient world».
\end{abstract}

\section{KEYWORDS:}

Greek and Roman religion, divination, Classical political theory, Greek law.

* Geschichte des Altertums / Klass. Philologie, Historisches Institut, Universität Potsdam (Am Neuen Palais, 10. 14469 Potsdam. Deutschland). E-mail: fuente@ uni-potsdam.de.

Artículo basado en la comunicación leída el 27 de Mayo de 2009, en la VIII edición del Encuentro de Jóvenes Investigadores de Historia Antigua de la Universidad Complutense de Madrid. 


\section{INTRODUCCIÓN}

Es bien sabido que las instancias fundamentales de la vida religiosa en la polis clásica -y aún en la ciudad griega en épocas helenística y romana- se situaban bajo la prestigiosa autoridad de la adivinación o techne mantiké . Entre las funciones de la adivinación, por tanto, se plantea una cuestión de gran relieve para el historiador de la Antigüedad: las implicaciones políticas y jurídicas en torno a las respuestas de los oráculos y adivinos. De hecho, más allá de la esfera privada, es bien sabido que gran parte de la actividad adivinatoria, tanto en Grecia como en Roma, se refería al gobierno de la ciudad y a las distintas acciones - políticas, comerciales o militares- que se fueran a emprender. Nada se hacía en la Antigüedad, desde este punto de vista, sin el visto bueno del dios, expresado a través de la adivinación y los profetas públicos: en la astrología babilónica, en los grandes santuarios griegos y en los augures romanos. Parece que en estas figuras se puede revelar una íntima ligazón entre la adivinación, y la política y la sociedad antigua.

No es una cuestión nueva en absoluto. Ya en 1842 el escritor y erudito Thomas De Quincey, al tratar de los oráculos griegos, sostenía que el antiguo santuario de Delfos «cumplía las funciones de un bureau d'administration central, una suerte de oficina general de información política y un órgano de coordinación universal de las deliberaciones de todo el pueblo helénico»»². Y hasta hoy día, la función política de la adivinación ha llegado a ocupar un lugar preeminente, más allá de los aspectos religiosos, en los estudios sobre los antiguos oráculos ${ }^{3}$.

Sin embargo, demasiadas veces se ha echado de menos una aproximación de conjunto y comparativa entre las diversas culturas de la Antigüedad. Interesante especialmente sería determinar en qué sentido la adivinación pudo condicionar la actividad política e incluso la disposición social del mundo antiguo, y estudiar el reflejo de los oráculos en los cambios en la distribución de las tierras, en las leyes de familia, en el derecho público o en la regulación de la ciudadanía. Son temas que plantean una enorme diversidad de cuestiones para el historiador de la Antigüedad: tal vez observar de cerca la evolución de los adivinos y oráculos pueda ser una de las mejores maneras de medir la temperatura política y social de las antiguas Mesopotamia, Grecia y Roma. Guerras, revueltas, conquistas, repartos de tierras y conflictos sociales, comerciales o religiosos, vistos a la luz de los antiguos oráculos que hacen referencia a ellos, tal vez adquieran nuevas dimensiones para su estudio.

1 La mántica es un fenómeno de gran complejidad que ha sido objeto de diversos estudios ya desde los comienzos de la crítica moderna, con la Histoire de la Divination, Bouché-Leclercq (1963). Últimamente se pueden mencionar los estudios de filosofía y mántica de Hogrebe (1992) y (2005), que han abierto nuevas perspectivas de gran interés para la comprensión de este fenómeno. Ha habido diversos panoramas críticos de conjunto, como Flacelière (1961), Parke (1967), Rosenberger (2001) o Hernández de la Fuente (2008).

2 Véase la edición española de su ensayo: De Quincey (2005).

${ }^{3}$ Cf. por ejemplo, la monografía sobre Delfos y la política ateniense de H. Bowden (2005) o, para la antigüedad mesopotámica, Koch-Westenholz (1994). 


\section{ADIVINACIÓN Y CONSTITUCIÓN POLÍTICA: DE CRETA A ESPARTA}

La legitimación del poder es, desde el punto de vista de la política, una función primaria de los oráculos. La consulta a la divinidad era obligada para ciertos asuntos de hondo calado, que concernían a legisladores, gobernantes y fundadores de ciudades. En ese sentido, en la Antigüedad grecolatina y seguramente como herencia oriental, hay figuras de grandes políticos legendarios que tienen especial relación con los oráculos, y que casi funcionan ellos mismos como sacerdotes y legisladores a la par, entre profetas y padres de la patria predestinados por la divinidad a dotar a la ciudad de sus leyes. Se trata de los theioi andres del mito y de la política griega arcaica - pensamos en Minos, por ejemplo- o de la antigua Roma, como Numa Pompilio ${ }^{4}$, que en sus coloquios con ciertas divinidades $u$ oráculos obtienen directrices para legislar y gobernar, en un arquetipo del folklore que ha representado desde el mundo semítico Moisés. Estas figuras semidivinas, hombres sagrados o, en la afortunada expresión de M. Detienne, maestros de ver$d a d^{5}$, tienen especial relación con la esfera mántica, en la vertiente de la consulta personal, el coloquio o comunión con la divinidad - synousía, en la terminología de Platón (Leyes 624a-b), hablando de Minos-, a fin de obtener las mejores leyes para los hombres. Como ya vio L. Gernet: «No sólo la religión y especialmente la práctica de la consulta religiosa está asociada al gobierno, lo que es normal para los griegos; sino que son los propios dirigentes del estado los que aparecen cualificados para entrar en contacto directo con la divinidad, y esta consulta personal es un procedimiento de gobierno ${ }^{6}$.

En la Grecia clásica, esta figura de homo sacer presenta un largo recorrido desde los mitos políticos y la historia de la Grecia arcaica, hasta la teoría política clásica y las utopías como las que formuló Platón en la República y en las Leyes. El legislador-profeta encuentra unos precedentes míticos en Grecia, como en otros pueblos, que bien pueden servir como paradigma para introducir la discusión en un encuentro interdisciplinario de historiadores, filósofos y filólogos como el que aquí se propone.

La antigua Creta, según un viejo mito, obtuvo sus leyes de Zeus a través de la figura de Minos, un mediador mágico a caballo entre dos mundos que representa desde Homero al legislador mántico ${ }^{7}$. Como hemos mencionado, Minos es el precedente mítico que simboliza este viejo arquetipo. Es un mediador que pasa nueve meses de sueño profético - incubatio o enkoimesis - en la gruta de Zeus para ser instruido acerca de la legislación. Creta es la isla de la legislación divina y toda investigación sobre las mejores leyes posibles debe, por ende, comenzar por allí: por Creta y su legislador mítico Minos ${ }^{8}$. De ellos heredará la ley divina la gran ciudad doria, Esparta. Según una primera versión, que transmite Heródoto,

\footnotetext{
4 Plut. Numa 6 y Cic. Sobre las leyes 1.4.13.

5 Detienne (2008: 27-28).

6 Gernet (1983: 29). La traducción es mía.

7 Cf. Hom. Od. 19.178; PI. Leg. 624a-b; Ps-PI. Minos 319d-e.

8 Schöpsdau (1994: 154).
} 
Esparta tomó las leyes divinas de Creta a través de su legislador Licurgo ${ }^{9}$. En las leyendas sobre la vida de Licurgo que transmite el biógrafo Plutarco (Lyc. 4-5), se afirma igualmente que viajó a Creta para estudiar la forma de gobierno de la isla y traer de vuelta a su Esparta natal las mejores de sus leyes. Licurgo aprende el arte de la legislación de un hombre divino, no del propio Minos, quizá por problemas de cronología mítica, sino de un hombre llamado Tales, poeta en apariencia pero cuyas obras funcionaban como leyes perfectas para los cretenses. Plutarco habla también de una visita de Licurgo a Egipto, donde habría aprendido la característica separación entre guerreros y trabajadores que se aplicaba en Esparta.

Según la otra versión, Esparta obtiene sus leyes directamente de Apolo, con la mediación de Licurgo como intermediario, a través de un oráculo délfico. Según Heródoto, los espartanos antes eran los griegos peor dotados de leyes hasta que Licurgo marchó a Delfos para consultar el oráculo recibiendo de la Pitia las leyes de Apolo $^{10}$, de las que se derivaría la famosa Rhetra fundacional de la legislación espartana ${ }^{11}$. Diodoro confirma esta versión más antigua del mito y añade unos versos al oráculo de Heródoto: «si vienes buscando una constitución / te daré el mejor gobierno entre todas las ciudades de la tierra» ${ }^{12}$. O sea, la constitución divina de Esparta, la famosa Rhetra, un sistema supuestamente divino que vuelve a traer a la tierra la edad de oro de los tiempos de Crono ${ }^{13}$. Licurgo ordena el culto, en especial a Zeus y Atenea, y divide la ciudad en tribus y hermandades estableciendo un Senado y dos reyes, un sistema de gobierno sacro al que se refiere Platón en otros lugares de las Leyes (696a-b).

Jenofonte presenta una combinación de las dos variantes: las leyes de Licurgo provienen de Creta y fueron más tarde sancionadas por Delfos ${ }^{14}$. Plutarco también transmite ambas versiones, la cretense y la consulta al oráculo ( $L y C$. 5): tras sus viajes, Licurgo habría visitado finalmente Delfos para recabar del dios las leyes espartanas. Esta doble tradición la recogen también las Leyes de Platón: por un lado, las leyes espartanas vienen de Delfos, pero por otro se pone de manifiesto la preeminencia de los cretenses, cuyas leyes copian los espartanos ${ }^{15}$. Platón comienza su gran diálogo legislativo con estas dos figuras, Minos y Licurgo, dos ciudades y dos ejemplos de ley divina.

\section{3. ¿LEY DIVINA EN ATENAS?}

Pero también en la tercera ciudad, la democrática Atenas, se puede decir que oráculo y ley aparecen entrelazados en los inicios. Y ello merced, de nuevo, a dos theioi andres a caballo entre la adivinación y la política, la literatura y la histo-

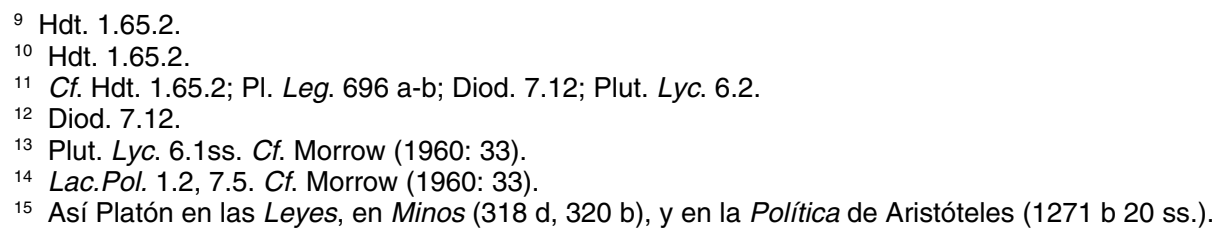


Oráculo y ley. Una aproximación a la influencia política de la adivinación en la Antigüedad...

ria: Solón de Atenas y Epiménides de Cnoso. En cuanto a Solón, según refiere Plutarco en la Vida que le dedicó, su acción política fue inspirada y favorecida por el oráculo, comenzando por la conquista de Salamina. Primero le ordenó cumplir un ritual y después encabezó la acción militar contra los megarenses, enemigos de Atenas. Mas no sólo en la guerra se inspiró en el dios de Delfos, sino que en su faceta de legislador (nomothetes) y mediador social (diallaktes) reformó la constitución ateniense bajo la guía del oráculo, que le dijo: «En medio de la nave el timón toma, y endereza su curso: que en tu auxilio tendrás a muchos de la ilustre Atenas». La legitimidad oracular como gobernante de Solón, elegido arconte en 594593 a.C. y uno de los Siete Sabios - cuyas máximas quedaron grabadas en el templo de Apolo en Delfos-, da fe de la especial relación de estos dos ámbitos, la mántica y la legislación constituyente, en la Grecia arcaica.

La otra figura que enlaza Atenas y sus instituciones predemocráticas - pero ya encaminadas a ser la escuela de la Grecia periclea-con el mundo arcaico cretense de la ley divina es el famoso Epiménides de Cnoso, profeta y poeta griego al que se atribuyó una gran amistad - personal y epistolar, según los biógrafos antiguoscon el legislador Solón. Este theios aner o maestro de verdad recorría, según la semblanza que de él hace Diógenes Laercio en el libro I de sus Vidas de filósofos ilustres, la Grecia antigua como sacerdote y taumaturgo, pero también como mediador político y religioso. Como una suerte de alter ego de Solón, Epiménides llega a Atenas - presumiblemente en torno a 595-592 a.C.- para purificar la ciudad de una peste que había causado la actuación del arconte Megacles, de la familia de los Alcmeónidas. Megacles había condenado a muerte a Cilón y sus partidarios, que a instancias de un oráculo délfico, se apoderaron de la Acrópolis para hacerse con el poder, pero lo había hecho cuando Cilón estaba acogido a sagrado, por lo que cayó una maldición sobre la ciudad. A Epiménides se le encargó la purificación ritual de Atenas y, a la par, la reconciliación política entre las diversas facciones de la ciudad. En ese sentido, constatamos su doble vertiente política y religiosa, que además refuerza el testimonio de Plutarco cuando afirma que Epiménides «luego que estuvo en Atenas, trabó gran amistad con Solón, a quien preparó y abrió el camino para su legislación, porque con los ritos sagrados hizo más económicos a los atenienses, y más moderados en sus duelos, intercalando con las obsequias ciertos sacrificios, y quitando lo agreste y bárbaro a que en estas ocasiones estaban acostumbradas muchas mujeres» (Sol. 12, trad. Ranz Romanillos).

En cierto modo, puede decirse que Epiménides encarna el vínculo entre la renovación política y la religiosa, que se obra merced a una sabiduría oracular a veces procedente del santuario délfico y otras directamente de la figura de un mediador divino y mántico. Cabe recordar que Epiménides también practicó, según diversos testimonios, la incubación: se dice que durmió varias décadas en una gruta cretense, tal vez la misma en que Minos recibiera la ley sagrada. Para Platón (Leg. 642d-643a), Epiménides marcha a Atenas «siguiendo un oráculo del dios», para ayudarles contra los persas - y prevenirles, según Diógenes Laercio, contra espartanos-. También vaticinó en su camino por Grecia a los lacedemonios su derrota ante los arcadios. Cuando murió —ia los 157 años! —, el cuerpo de este profeta legendario - - , según algunas tradiciones, su piel— fue conservado en Es- 
parta como una suerte de talismán siguiendo un oráculo (Diog.Laert. 1.114 ss.). Pero también se cuenta que los espartanos lo mataron porque les profetizaba cosas poco favorables y que en realidad estaba enterrado en Argos (Paus. 2.21.3). Epiménides, en fin, es el vínculo entre Atenas y el mundo dorio de la ley divina desde Creta, su lugar de origen, a Esparta-, como el mejor ejemplo de 'hombre divino'. En este gran adivino político de la Grecia antigua confluyen las diversas vertientes de esta tradicional figura que sirve para enlazar oráculo del dios y ley de los hombres en la antigua mitología y literatura griega.

\section{EL ORÁCULO COMO FUENTE DE DERECHO: DEL MITO A LA HISTORIA}

Después de este panorama acerca del tema mítico de la legislación divina y sus relaciones con la mántica, procede terminar con un apunte - muy breve por necesidad-sobre la presencia histórica de los oráculos en las leyes históricas del mundo griego antiguo. No conviene olvidar que la techne mantiké estuvo muy presente también en el diseño de la convivencia social, como autoridad que emanaba de los cielos, desde la Grecia arcaica hasta la helenística. Portavoz de la voluntad de los dioses, el oráculo - y sobre todo Delfos- tenía gran influencia en la regulación del culto, la implantación de nuevas divinidades o rituales, el traslado y honra de restos mortales de héroes, la administración de áreas sagradas, el nombramiento de sacerdotes, etc. ${ }^{16}$ La voz del dios era consultada a menudo para cualquier alteración en las leyes no escritas de la tradición religiosa ${ }^{17}$ : el derecho sagrado tenía una clara fuente en la mántica, como se ve en ejemplos abundantes en la época clásica y helenística, recogidos en las colecciones al uso de leges sacrae, que compiló en su día Sokolowski $(1955 ; 1962 ; 1969)$ y que recientemente se han visto acrecidas por el trabajo de Lupu (2005).

En ese sentido, entendemos 'ley sacra' como aquella ley que regula aspectos formales del culto religioso: elección de sacerdotes, administración de templos o sus peculios, ordenamiento de festivales. Pero también se tratan asuntos de fondo, normativizando la práctica ritual y estableciendo cómo hay que rendir culto, cómo se debe sacrificar, cómo vestirse para ello, etc. ${ }^{18}$ Esta ley sacra, o derecho concerniente a lo sagrado - ta hierá o ta theiá - era parte de la ley ancestral - ta patria- que resistió durante más tiempo a la codificación por escrito precisamente por ser percibida como procedente del mundo divino. Dentro de ella, además, la crítica ha diferenciado el derecho sagrado ${ }^{19}$, las formas religiosas de acción —sobre todo el juramento, pero también la magia o la maldición- que eran jurídicamente vinculantes en el proceso legal en Grecia.

16 Cf. en general Parke (1939: 325 ss.). El ejemplo de los huesos de Orestes: Hdt. 1.67-68; Paus.

3.3.5-6; Diod. 9.36.3. El de los huesos de Teseo: Plut. Tes. 36.1; Paus. 3.3.7.

17 Parker (2005: 62).

18 Un ejemplo en Sokolowski (1969: 97).

19 Heiliges Recht, en la terminología acuñada por Latte (1920). 
Oráculo y ley. Una aproximación a la influencia política de la adivinación en la Antigüedad...

En cuanto a asuntos religiosos, el oráculo era la fuente primordial del derecho. Sus vaticinios eran conservados oralmente en las tradiciones cultuales, en las costumbres inveteradas y en la sabiduría proverbial, y por escrito en los poemas de Homero, Hesíodo, Museo, Orfeo y otros. Además, a la vez, era la máxima instancia a la que acudir en caso de duda o controversia, pues, en palabras de Morrow, «existía una fuente viviente del derecho religioso: las respuestas del oráculo a los consultantes contemporáneos ${ }^{20}$.

Los santuarios oraculares, desde época arcaica hasta bien avanzada la edad romana, refrendaron ciertos puestos y magistraturas de las póleis griegas, especialmente las dedicadas a funciones religiosas. Un ejemplo de consulta para establecer los términos de la elección de sacerdotes se encuentra en una inscripción con un oráculo de Dodona del siglo $\mathrm{V}$ a.C. ${ }^{21}$ Seis siglos más tarde, ya en el primero de nuestra era, una consulta de la ciudad de Heraclea interrogaba al dios si la magistratura religiosa de Atenea Latmia debía ser renovada anualmente u ostentada de por vida por una persona ${ }^{22}$.

Sin embargo, al menos desde el siglo VI al III a.C., los oráculos funcionaron como fuente de derecho para otros asuntos que, aunque aparentemente relacionados con la religión, encerraban aspectos de derecho civil y político. Un ejemplo lo ofrecen las consultas para temas de ciudadanía. Así sucede, en un ejemplo del siglo VI a.C., con la célebre reforma de Clístenes en Atenas, tradicionalmente reconocida como fundamento de la democracia y la igualdad ante la ley -isonomía - En el año 510 a.C., decidió abolir las antiguas asociaciones de clanes en Atenas y reemplazarlas con diez tribus - philai-, artificialmente creadas, según su demo de residencia entre las tres regiones de la ciudad: la ciudad, la costa y el interior. Cada philé debía recibir el nombre de un héroe tutelar y Clístenes consultó al oráculo de Delfos para saber qué dios debía ser el patrón de cada una, como refiere Aristóteles ${ }^{23}$. En palabras de Burkert, «un acto de esta naturaleza no era simplemente una medida administrativa: el dios de Delfos fue consultado para seleccionar aquellos cuya adoración sería mejor y más beneficiosa» ${ }^{24}$. Aunque no se pedía refrendo directo a la decisión en sí y la consulta se refería al culto, es indudable el trasfondo de reorganización político-social de la ciudadanía.

En las póleis griegas de edad clásica y helenística, las leyes religiosas controlaban la pertenencia a la comunidad política y la entrada en la misma de grupos foráneos. En Atenas, la conocida reforma de Pericles en 451 a.C., refrendada por la autoridad religiosa, exigía padre y madre atenienses para ser ciudadano. En una clara atribución civil, el oráculo era consultado en lo que se refería a la legitimación de grupos de población extranjera. Un buen ejemplo es un oráculo de Dídima de

\footnotetext{
20 Morrow (1960: 408). La traducción es mía.

$21 \mathrm{IG} \mathrm{I}^{3} 136$.

22 SEG xl 956 Ila.

23 Ath.Pol. 21.6; Paus. 10.10.1.

24 Burkert (1985: 206). La traducción es mía.
} 
234-3 a.C., conservado en una inscripción ${ }^{25}$, que recomendó conceder la ciudadanía a mercenarios de origen cretense que habían luchado por la ciudad de Mileto en un momento de conflicto con la ciudad de Magnesia del Meandro (10-11).

El saber divino, como herencia de la época arcaica y de los tiempos «cuando la religión dio a los hombres la fuerza para crear para sí mismos la ley y el estado»²6, inspira en cierto modo todo el sistema legal de la polis —educación, derecho civil y penal, organización religiosa, etc.- . También a la hora de resolver conflictos, como se ve en este último ejemplo: por falta de ciudadanos y en un momento políticamente difícil, se opta por incorporar colonos a la comunidad. Parece que el testimonio de Milet I 3.33 es un buen ejemplo para proponer un esquema de los casos de consulta política del oráculo más usuales. Aunque se trata de un análisis que excede las pretensiones de este texto, se puede considerar que los usos y momentos de consulta política del oráculo en la tradición histórica son:

1. Momentos fundacionales (oikismós).

2. Momentos constituyentes (nomothesía).

3. Momentos de conflicto social:

3.a. Prevención.

3.b. Mediación y resolución: derecho penal, civil, religioso.

4. Modificaciones del ordenamiento jurídico; por ejemplo: introducción del culto a nuevos dioses o nuevos héroes, concesiones y confirmaciones de sacerdocio, modificaciones constitucionales.

Curiosamente, y como creemos haber demostrado en otro lugar ${ }^{27}$, estos casos coinciden con el detallado plan de uso legal de los oráculos que proyecta Platón en la utopía de sus Leyes. Se trata, en todo caso, de una clasificación que puede sentar las bases de un futuro estudio exhaustivo sobre el uso de los oráculos en el derecho griego. Y es que oráculo y ley se tocan de cerca y la adivinación se perfila no sólo como fuente de derecho, sino también como instancia de resolución de conflictos e instrumento de control social y legitimación política. Y es que la adivinación, aparte de su función puramente religiosa y ritual, sirvió, desde los viejos theioi andres del mito y de la política arcaica hasta los oráculos helenísticos, como una suerte de motor ideológico no sólo en cuanto a los esquemas narrativos del pensamiento mítico, sino también para la política, el derecho, y, cómo no, para el debate filosófico. Más allá del recurso a la comunicación con los dioses en dichas esferas, los oráculos fueron también uno de los mecanismos más importantes de control político y social en la Antigüedad.

${ }^{25}$ Milet I 3.33. Cf. también Rodríguez Somolinos (1991: OD n. ${ }^{\circ}$ ). Ver la contribución de Federica Pezzoli en este volumen.

${ }^{26}$ Latte (1920), en Parker (2009 : 69). La traducción es mía.

27 "Oracles as sources of law and Plato's reinterpretation in the Laws», 13ième Congrès de la FIEC (Fédération internationale des Associations d'études classiques), Humboldt-Universität zu Berlin, Panel 16, 28 de agosto de 2009. Inédito. 
Oráculo y ley. Una aproximación a la influencia política de la adivinación en la Antigüedad...

\section{A MODO DE CONCLUSIÓN: ADIVINACIÓN Y POLÍTICA}

Como apuntan estas breves notas, un estudio de la adivinación y su influencia política y jurídica -ya sea en el plano constitucional o en el del ordenamiento jurídico aplicado a conflictos sociopolíticos- puede arrojar luz sobre aspectos muy variados de la historia de la Antigüedad. Sobre la base de los textos literarios, políticos y legales, el historiador y el filólogo deben ejercer de estudiosos de los fenómenos religiosos para entender la intersección entre los ritos adivinatorios y la política antigua. De tal manera, al idear esta mesa redonda, ahora convertida en publicación, nos proponíamos recoger las posibles aportaciones en este sentido. A la vez se quería ofrecer un panorama sobre la relación entre adivinación y política, y discutir casos particulares, comparando los puntos de contacto, en Grecia y Roma pero también en sus precedentes egipcios o mesopotámicos.

Así, comenzando por el antiguo Egipto, la primera contribución que se presenta en este apartado trata la adivinación y praxis política en Egipto. En ella, Jorge Alberto Ordóñez Burgos (UA, Ciudad Juárez) revisa la escala y el orden cósmico del mundo egipcio reflejada en la práctica política del imperio gracias a la intermediación mántica. Egipto será el espejo en que se miren los griegos y los romanos en cuanto al estudio de las formas religiosas y de gobierno; y la figura del legislador profeta posiblemente pueda remontarse a ese paradigma prestigioso ${ }^{28}$. Ya entrando en el mundo clásico griego, la contribución de Giuliana Besso (Università degli Studi di Torino) analiza la intersección entre oráculo y tiranía en el caso de Falaris de Agrigento. El componente religioso y la propaganda mítica -también reflejada en los oráculos- desempeñaron un papel fundamental en el programa político de la tiranía, como se ve en las anécdotas al respecto transmitidas por Ateneo.

Dos intervenciones, de Maria Eugenia de la Nuez Pérez (Université Bourdeaux) y de Federica Pezzoli (Università degli Studi di Torino) ponen de relieve la importancia política del oráculo de Apolo en Dídima en época helenística. La primera contribución ofrece un panorama sobre los oráculos vinculados a la dinastía seléucida, los de Apolo en Claros y Dídima, con una evidente función de legitimación política. La refundación y la promoción evergética de los santuarios de Apolo bajo el Imperio Seléucida responde a una cierta apropiación de sus respuestas para fines propagandísticos, como evidencia el texto que presenta De la Nuez. La segunda contribución estudia con detalle un caso paradigmático de uso sociopolítico del oráculos, que hemos mencionado algo más arriba: se trata de la inscripción Milet I 3.33, por medio de la que se integran en la ciudad de Mileto nuevos ciudadanos de origen cretense. El artículo de Pezzoli arroja luz sobre las circunstancias históricas de este episodio, cuando en pleno momento de crisis se decide incorporar colonos a la ciudad otorgándoles lotes de tierra y prohibiendo su venta durante 20 años.

${ }_{28}$ Un buen ejemplo de ello es el Busiris de Isócrates, irónico ejemplo de rey, profeta y legislador modelo con posibles referencias a las ideas políticas de Platón. 
Finalmente, la última contribución, a cargo de Diony González Rendón (Universidad Carlos III de Madrid), versa sobre la conocida obra Sobre la adivinación (De divinatione) de Cicerón. El texto propone un acercamiento a esta obra desde el contexto político del momento de crisis de la República romana y estudiarla atendiendo a una perspectiva biográfica de su autor, sin dejar de lado lo que de sus convicciones religiosas acerca de la mántica trasluce De divinatione.

Gran variedad de cuestiones e implicaciones, como puede verse, están contenidas en los textos que se recogen en esta ocasión. En todos ellos, sin embargo, en sus tratamientos particulares de casos concretos o en sus visiones de conjunto, se detectan algunas notas comunes que ponen de manifiesto el notable interés de este tema. Algunas de las funciones políticas que hemos notado en estos apuntes con respecto a los oráculos griegos - y también en otros tipos de adivinación en la Antigüedad - se pueden resumir en varios aspectos fundamentales: 1) legitimación: la adivinación otorga un aura de legitimación política a los legisladores y gobernantes de todas las épocas que hacen uso del recurso a la ley divina por mediación mántica; 2) unificación: se usa la voluntad divina para unificar leyes, costumbres, pueblos; 3) vinculación: el oráculo une a los hombres con los dioses y garantiza la procedencia divina de ciertas disposiciones, decisiones, o usos legales; 4) intermediación: a la vez, el oráculo o adivino se erige en mediador privilegiado entre las esferas divina y humana, en las que se mueve la ley como un código que emana en principio del ámbito religioso y cultual.

Como se consignaba al comienzo de estas líneas, la observación detallada de la historia de los adivinos y oráculos en la Antigüedad puede otorgar una visión privilegiada de la evolución política y social de las culturas antiguas, desde Egipto y Mesopotamia a Grecia y Roma. El oráculo como pulso administrativo y político del mundo antiguo - lo que ya viera De Quincey hace más de 150 años- perderá su relevante papel con el advenimiento del Cristianismo, que desempeñó durante siglos una función análoga en muchos casos. Hoy son otros los oráculos que preocupan a nuestros políticos y de nombres muy variados.

\section{BIBLIOGRAFÍA}

BOUCHÉ-LECLERCQ, A. (1963), Histoire de la Divination dans l'Antiquité, 4 vols., París. BOWDEN, H. (2005), Classical Athens and the Delphic Oracle. Divination and Democracy, Cambridge.

- (1985), Greek Religion. Archaic and Classical, Oxford.

DE QUINCEY, T. (2005), Los Oráculos Paganos y otras Obras Selectas, Madrid.

DETIENNE, M. (2008), I Maestri di Verità nella Grecia Arcaica, Bari.

FLACELIĖRE, R. (1961), Divines et Oracles Grecs, Paris.

GERNET, L. (1983), Les Grecs sans Miracle, Paris.

HERNÁNDEZ DE LA FUENTE, D. (2008), Oráculos Griegos, Madrid.

HOGREBE, W. (1992), Metaphysik und Mantik, Frankfurt am Main.

HOGREBE, W. ed. (2005), Mantik. Profile prognostischen Wissens in Wissenschaft und Kultur, Würzburg.

KOCH-WESTENHOLZ, U. (1994), Mesopotamian Astrology: An Introduction to Babylonian and Assyrian Celestial Divination, Copenhague. 
Oráculo y ley. Una aproximación a la influencia política de la adivinación en la Antigüedad...

LATTE, K. (1920), Heiliges Recht. Untersuchungen zur Geschichte der sakralen Rechtsformen in Griechenland, Tübingen.

LUPU, E. (2005), Greek Sacred Law. A Collection of New Documents, Leiden.

MORROW, G. R. (1960), Plato's Cretan city: a Historical Interpretation of the Laws, Princeton.

PARKE, H. R. W. (1939), History of the Delphic Oracle, Oxford.

- (1967), Greek Oracles, London.

PARKER, R. (2005), «Law and religion», in Gagarin, M. y Cohen, D. eds., The Cambridge Companion to Ancient Greek Law, Cambridge, 61-81.

RODRÍGUEZ SOMOLINOS, J. (1991), Los Oráculos de Claros y Dídima. Edición y Comentario, Madrid.

ROSENBERGER, V. (2001), Griechische Orakel: Eine Kulturgeschichte, Darmstadt.

SOKOLOWSKI, F. (1955), Lois Sacrées de l'Asie Mineure, Paris.

- (1962-1969), Lois Sacrées des Cités Grecques, Paris.

SCHÖPSDAU, K. ed. (1994), Platon. Nomoi I-III, Göttingen. 